Research Journal of Applied Sciences 6 (5): 335-343, 2011

ISSN: $1815-932 \mathrm{X}$

(C) Medwell Journals, 2011

\title{
Effects of Freeze Vacuum Drying and Heating from Condenser's Heat Loss on Drying Rate and Microstructure of Aloe Vera
}

\author{
Nasruddin M. Idrus Alhamid, Engkos A. Kosasih and Muhamad Yulianto \\ Department of Mechanical Engineering, Universitas Indonesia, \\ 16424 Kampus UI Depok, Indonesia
}

\begin{abstract}
This study presents an effect heating from condenser's heat loss from top and bottom positions of the extraction process using freeze vacuum drying on drying rate, drying time and microstructure of aloe vera. Extraction by thermal process involves removing water contained inside the aloe vera and releasing it into the environment. Freeze Vacuum Drying (FVD) can be used to extract aloe vera without impairing its structure, color or nutritional value although the process requires a high level of energy consumption. Results of the experiments showed that capturing and using heat from a condenser's heat loss increased the drying rate and reduced drying time. Heater temperatures at the top and bottom positions were 22 and $30^{\circ} \mathrm{C}$, respectively for a combination heater temperature at the top was 26 and $24^{\circ} \mathrm{C}$ at the bottom changes in microstructure were examined by Scanning Electron Microscopy (SEM).
\end{abstract}

Key words: Freeze vacuum drying, aloe vera, condenser's heat loss, microstructure, Indonesia

\section{INTRODUCTION}

Freeze Vacuum Drying (FVD) is an optimal drying technology method because it maintains the structure, nutrients and color of the original substance (George and Datta, 2002; Chakraborty et al., 2006; Ghio et al., 2000). Freeze vacuum drying has also been described as a method of drying that achieves a high drying rate because the boiling point of water in the product, held under the vacuum is lower than atmospheric pressure and water vapor is removed by a vacuum pump Holkeboer et al. (1993). Consequently, FVD is suitable for the extraction of basic medical ingredients (Mujumdar, 2008). A weakness of FVD is its high consumption of energy (Mujumdar, 2008) due to the long drying time required especially in the process of sublimation below triple point condition (pressure of $6.1 \mathrm{mbar}$ and temperature of $0^{\circ} \mathrm{C}$ ) as shown in Fig. 1 (Oetjen and Haseley, 2004) a high level of energy is also required for the refrigeration system which is used as a cold trap. Figure 1 shows that at initial condition, the material was in atmospheric condition (pressure $1000 \mathrm{mbar}$ and temperature $27^{\circ} \mathrm{C}$ ) from the liquid phase, pressure was reduced and triple point condition in solid phase was observed followed by saturation condition, the material change phase from solid to gas known as sublimation which was observed until the material reached $27^{\circ} \mathrm{C}$. We noted that consumption of energy during the sublimation

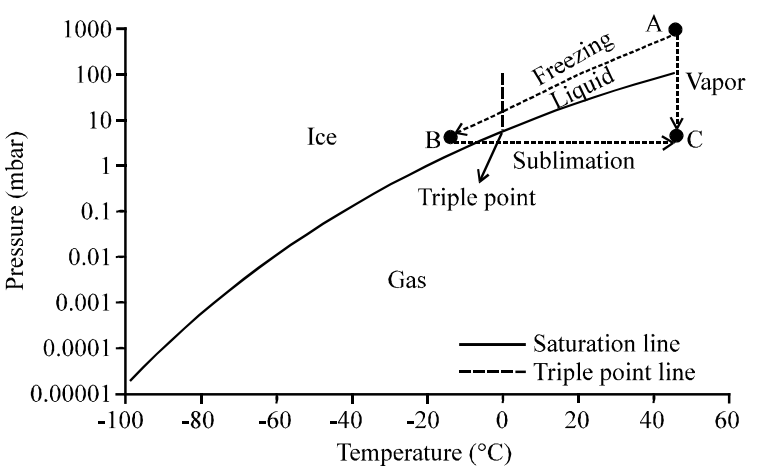

Fig. 1: Schematic of water properties on P-T diagram

process due to very slow mass and heat transfer rates can be achieved under vacuum conditions to provide heat sublimation by either conduction or radiation without exceeding the triple point (Mujumdar and Law, 2010).

In general, prolonged drying time can be reduced by techniques such as increasing temperature or decreasing pressure in the chamber. An experiment with FVD using a microwave heat source was developed for drying potato slices (Wang et al., 2010) and the total drying time was reduced by $37 \%$ as a result of microwave freeze drying and not conventional freeze drying. Results of another experiment using microwave freeze drying for drying sea cucumbers indicated that the technique can effectively replace conventional freeze drying because it greatly

Corresponding Author: Nasruddin M. Idrus Alhamid, Department of Mechanical Engineering, Universitas Indonesia, 16424 Kampus UI Depok, Indonesia 
reduces drying time and energy consumption while producing the same product quality. In order to avoid corona discharge during microwave freeze drying, the cavity pressure should be applied within the range of 50-100 Pa (Duan et al., 2008; Huang et al., 2011). An experiment using an electrical heat source in the top position of a freeze vacuum dryer was conducted for drying foodstuff; the surface temperature of the sample initially increased quickly due to the higher initial temperature difference between the sample surface and electrical heater, resulting in an increase in the drying rate and a reduction in drying time (Chakraborty et al., 2006). Other experiments using electrical heat sources have been performed to compare differences attributable to placement of aloe vera in either top or bottom positions resulting in a faster drying rate at the bottom position (Belyamin et al., 2007). This phenomenon occurred because the thermal conductivity of ice or a frozen layer, if using a bottom position heater is 45 times higher than the thermal conductivity of a dry layer if using a top position heater (Mellor, 1978). An innovative experiment using infrared radiation as a heat source when drying peaches was compared to microwave freeze drying and results showed that less energy was consumed using infrared radiation (Wang and Sheng, 2006).

Recently, chili peppers were freeze dried using a heat pump inside a product container and a dehumidifier and blower to reduce humidity at the drying chamber, resulting in reduced drying time accomplished from either reducing drying pressure or from increasing drying temperature. The moisture content of $20 \mathrm{~kg}$ of fresh chilies was reduced from $34-15 \%$ when dried for $7 \mathrm{~h}$ (Artnaseaw et al., 2010). This experiment, along with the ones mentioned above show that electrical, microwave infrared and heat pump heating can be used in FVD but each method requires a high level of energy consumption to operate the apparatus. The other problem when using heaters to reduce drying time during FVD is that the heating temperature must be controlled to prohibit deterioration of certain materials. Each material exhibits a certain resilience to receiving heat; materials used for medicinal purposes for example have a maximum heating value of $60^{\circ} \mathrm{C}$ (Mujumdar, 2008). The main challenge in freeze vacuum drying therefore is reducing energy consumption during heating while maintaining high product quality especially for basic medical ingredients.

Within FVD equipment, the cold trap traps moist air from the drying chamber to prevent damage to the vacuum pump (Oetjen and Haseley, 2004). A cold trap is made from a refrigeration system which consists of a compressor, condenser, expansion valve and evaporator.
The compressor increases pressure of the refrigerant to change phases from liquid to gas, thereby producing a large amount of heat. The expansion valve only accepts the refrigerant in liquid phase and the condenser removes heat from the system and releases it to the environment. Subsequently, variations in temperature produce potential energy that can be exploited (Dincer, 2003).

Aloe vera is one of many herbal plants commonly grown in Indonesia which can be used for medicinal purposes. In pharmaceuticals, it is used as an antiinflammatory agent, anti-oxidant, laxative, antimicrobial and molusisidal, anti-cancer agent and hepato protector having a moisture content of $98.7 \%$. Nutrient loss is observed when structural damage of the substance occurs (Lee and Rhee, 2007; Acevedo et al., 2007; Deng and Zhao, 2008; Njintang et al., 2008). Therefore, the structure of aloe vera should be observed after the freeze drying process. The purpose of using FVD when drying aloe vera is to preserve its structure.

The objective of this research is to study the effects of the heating temperatures from the condenser's heat loss at the top and bottom positions of the range which vary from $22-30^{\circ} \mathrm{C}$ and also the temperature combination (top $26^{\circ} \mathrm{C}$ and bottom $24^{\circ} \mathrm{C}$ ) on the drying rate, microstructure and performance of the refrigeration system (cold trap) in addition to energy savings based on shorter drying times.

\section{MATERIALS AND METHODS}

Experimental set-up and the operation of equipment: $A$ prototype of a freeze vacuum dryer with top and bottom heater positions and a heat source from a condenser's heat loss was designed and installed by the Laboratory of Refrigeration, Department of Mechanical Engineering, University of Indonesia (Fig. 2). A schematic diagram of this equipment is included in this study (Fig. 3). This equipment consists of two cylindrical rooms for drying and a cold trap chamber. Energy is required to operate the vacuum pump $(2.2 \mathrm{~kW})$ and compressor within the refrigeration system $(0.75 \mathrm{~kW})$. Pressure of the drying chamber was measured using a pressure transmitter PTX 1400 with a range from $0-4$ bars and an accuracy of $0.4 \%$. The pressure of the discharge from the compressor also measured by the pressure transmitter PTX 1400 was $0-40$ bars with an accuracy of $0.4 \%$. Temperatures of the drying chamber, cold trap chamber, product/material, top and bottom heaters, suction and discharge compressor, suction and discharge condenser and suction evaporator were measured by a thermocouple type K (TEX/TEX-30- 


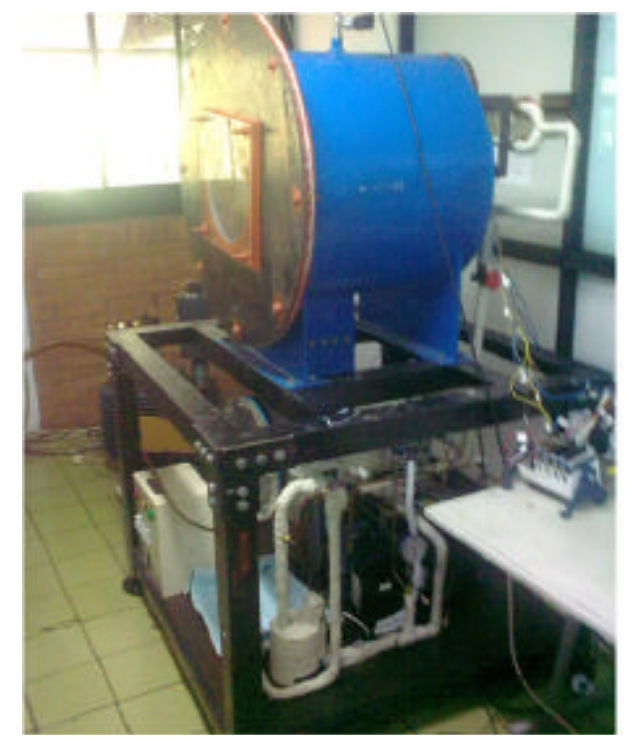

Fig. 2: Freeze vacuum drying system with heat source from heat loss condenser

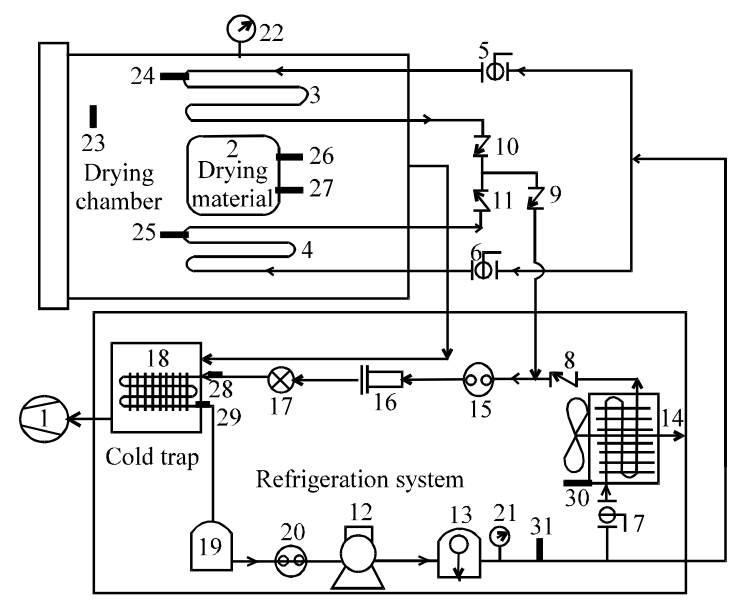

Fig. 3: Schematic diagram of the freeze vacuum dryer 1. Vacuum pump, 2. Substance (Aloe vera), 3. Top heater, 4. Bottom heater, 5-7. Shut-off valve (ball valve), 8-11. Check valve, 12. Compressor, 13. Oil separator, 14. Condenser, 15. Sight glass, 16. Filter dryer, 17. Expansion valve, 18. Evaporator (cold trap), 19. Accumulator, 20. Sight glass, 21-22. Pressure transmitter, 23-31. Thermocouple

KK) with an accuracy of $0.4 \%$. Aloe vera weight was measured on a digital balance range was $0-600 \mathrm{~g}$ with an accuracy of $0.4 \%$. The cold trap (refrigeration system) operated on refrigerant $\mathrm{R} 22$.

To start the process, the refrigeration system was turned on until the cold trap or evaporator reached a temperature of $-40^{\circ} \mathrm{C}$. The vacuum pump was then turned

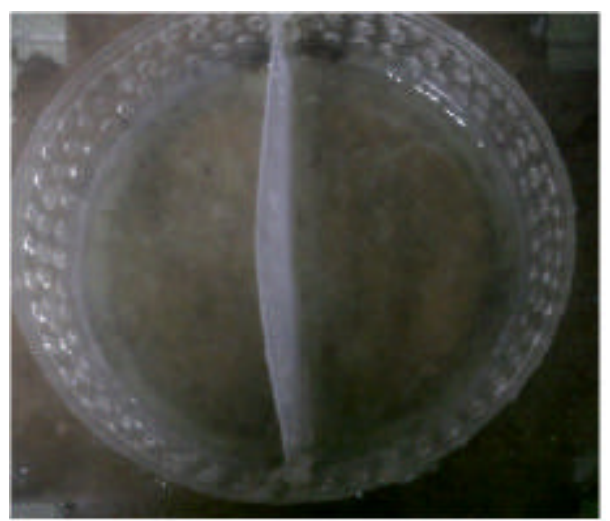

Fig. 4: Initial condition of aloe vera

on until the substance reached a temperature of $-7^{\circ} \mathrm{C}$ and appeared stable. Heating temperatures from the condenser's heat loss were $30^{\circ} \mathrm{C}$ as the top heater, $30^{\circ} \mathrm{C}$ as the bottom heater and for the combination heater, $26^{\circ} \mathrm{C}$ at the top position and $24^{\circ} \mathrm{C}$ at the bottom position. A continuous process took place until the substance was in dried condition.

Sample preparation: Aloe vera is a commonly grown variety in Indonesia used as a basic medical ingredient. To obtain a desired weight of sample when dried, aloe vera is first stirred and measured (Fig. 4); its characteristics in initial condition are moisture content of $98.7 \%$ granular consistency and green or brown color.

Microstructure: Coated specimens were inspected for microstructures measuring $20 \mathrm{~mm}$ in diameter and $3 \mathrm{~mm}$ in thickness.

Specimen fragments were mounted on aluminum stubs, coated with gold and photographed using the Scanning Electron Microscope (SEM), LEO 420i with an accelerating voltage of $12 \mathrm{kV}$.

Moisture content: The moisture content of aloe vera in the drying process was calculated by using the following equation (Menlik et al., 2010):

$$
\mathrm{MC}_{\mathrm{db}}=\frac{\mathrm{m}_{\mathrm{i}}-\mathrm{m}_{\mathrm{d}}}{\mathrm{m}_{\mathrm{d}}}
$$

Where:

$\mathrm{Mc}_{\mathrm{db}}=$ Moisture content at specific time $\mathrm{t}$ on a dry basis $\left(\mathrm{g} \mathrm{g}^{-1}, \mathrm{~d} . \mathrm{b}\right)$

$\mathrm{m}_{\mathrm{i}}=$ The weight of the substance at time $\mathrm{t}$

$\mathrm{m}_{\mathrm{d}}=$ The dry matter weight of the material

$\mathrm{t}=$ The drying time $(\mathrm{h})$ 


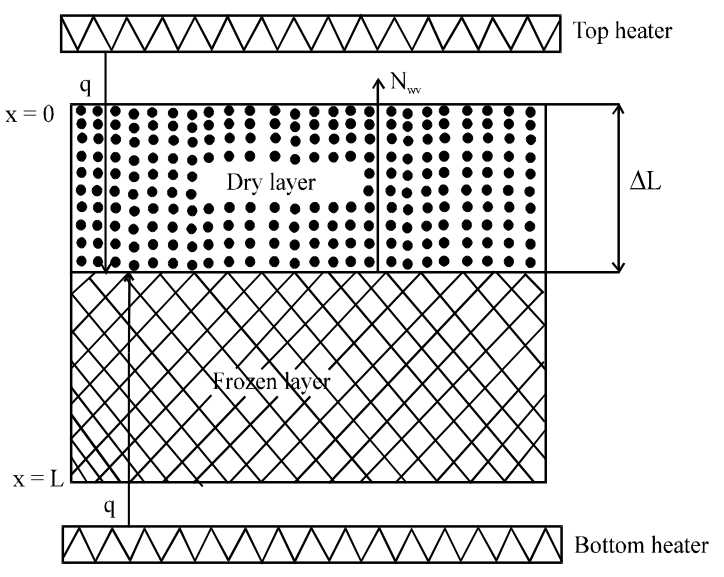

Fig. 5: Material scheme for heat and mass flux

Drying rate: Figure 5 shows the heat and mass flux responsible for moisture transfer from the frozen sample in FVD. It should be noted that the heaters (top and bottom) from condenser's heat loss were maintained at higher temperatures than the sample so that the heat transfer process could occur. Therefore, heat flux took place through the frozen layer (if bottom heater) and the dried layer (if top heater). Based on heat flux, we assumed the following calculations (George and Datta, 2002; Chakraborty et al., 2006).

$$
\begin{aligned}
& \mathrm{q}=\frac{\lambda}{\mathrm{L}-\Delta \mathrm{L}}\left(\mathrm{T}_{\mathrm{h}}-\mathrm{T}_{\mathrm{f}}\right) \\
& \Delta \mathrm{L}=(1-\mathrm{x}) \mathrm{L}
\end{aligned}
$$

Substituting:

$$
\mathrm{q}=\frac{\lambda}{\mathrm{xL}}\left(\mathrm{T}_{\mathrm{h}}-\mathrm{T}_{\mathrm{f}}\right)
$$

The equation of mass flux describes the process due to heat flux (Fig. 5):

$$
\mathrm{q}=\Delta \mathrm{h} \cdot \mathrm{N}_{\mathrm{ws}}
$$

Due to mass transfer $\left(\mathrm{N}_{\mathrm{wv}}\right)$ is based on function time and thickness of dry layer then equation becomes:

$$
\mathrm{q}=\mathrm{N}_{\mathrm{wv}}\left(-\frac{\mathrm{dx}}{\mathrm{dt}}\right) \cdot \Delta \mathrm{h}
$$

Substituting from Eq. 3 we get:

$$
\begin{gathered}
\operatorname{Nwv}\left(-\frac{\mathrm{dx}}{\mathrm{dt}}\right) \cdot \mathrm{h}=\frac{\lambda}{\mathrm{xL}}\left(\mathrm{T}_{\mathrm{h}}-\mathrm{T}_{\mathrm{f}}\right) \\
\text { Nwv..L } \int_{1}^{\mathrm{x}}-\mathrm{x} . \mathrm{dx}=\lambda\left(\mathrm{T}_{\mathrm{h}}-\mathrm{T}_{\mathrm{f}}\right) \int_{0}^{\mathrm{t}} \mathrm{dt}
\end{gathered}
$$

Energy consumption: Energy of FVD was consumed for:

- Vacuum pump, type DRP-1400 Ogawa Seiki Co., Ltd., constant at $2.2 \mathrm{~kW}$

- $\quad$ Refrigeration (cold trap) system, constant with power of compressor at $0.75 \mathrm{~kW}$ and condenser fan at $53 \mathrm{~kW}$

- Ice sublimation or heating ice with energy used for the phase changes from solid to gas

The equation to describe energy consumption was previously developed (Sharma and Prasad, 2006).

$$
\mathrm{H}_{\mathrm{c}}=\frac{\mathrm{h}_{1}+\mathrm{h}_{2}+\mathrm{h}_{3}}{\mathrm{~W}_{\mathrm{e}}}
$$

\section{RESULTS AND DISCUSSION}

Profile of substance temperature from beginning to end of FVD process: Figure 6 shows the variation of the substance's surface temperature during the freeze drying process with variations in heating temperatures such as no heat, top heating of $30^{\circ} \mathrm{C}$, bottom heating of $30^{\circ} \mathrm{C}$ and combination heating (top heating $26^{\circ} \mathrm{C}$ and bottom heating $24^{\circ} \mathrm{C}$ ). The process started with the freezing process whereby the temperatures were reduced by the vacuum process. This phenomenon occurred due to the continuous process of taking latent heat from water evaporation of the substance in the low pressure chamber so that the temperature of the material was reduced and frozen (Carapelle et al., 2001; Shishehgarha et al., 2002). After the freezing process reached the saturation point at a temperature of $-7^{\circ} \mathrm{C}$, the next process was sublimation which provides FVD with an advantage over other conventional drying techniques that use evaporative methods (Ghio et al., 2000). Sublimation consists of main drying and secondary drying. When main drying occurred, most of the free water was transferred to the environment. When secondary drying took place, evidence of non-frozen free water and bound water indicated the desorption step (Wang et al., 2010). Completion of FVD showed that the temperature of the substance increased until it reached the ambient temperature after all moisture in the material in its solid form had sublimated (Idrus et al., 2010).

Moisture content (dry basis) and energy consumption: Table 1 shows all experiments with variances in top and bottom heating. The initial moisture content of aloe vera was $98.7 \%$ and the content level decreased along with drying time in all drying processes. Final moisture content was stable until it reached Equilibrium Moisture Content (EMC). The final moisture content of aloe vera in the experiment reach approximately $2.5 \%$ with varying drying times and heating temperatures at the top and bottom 


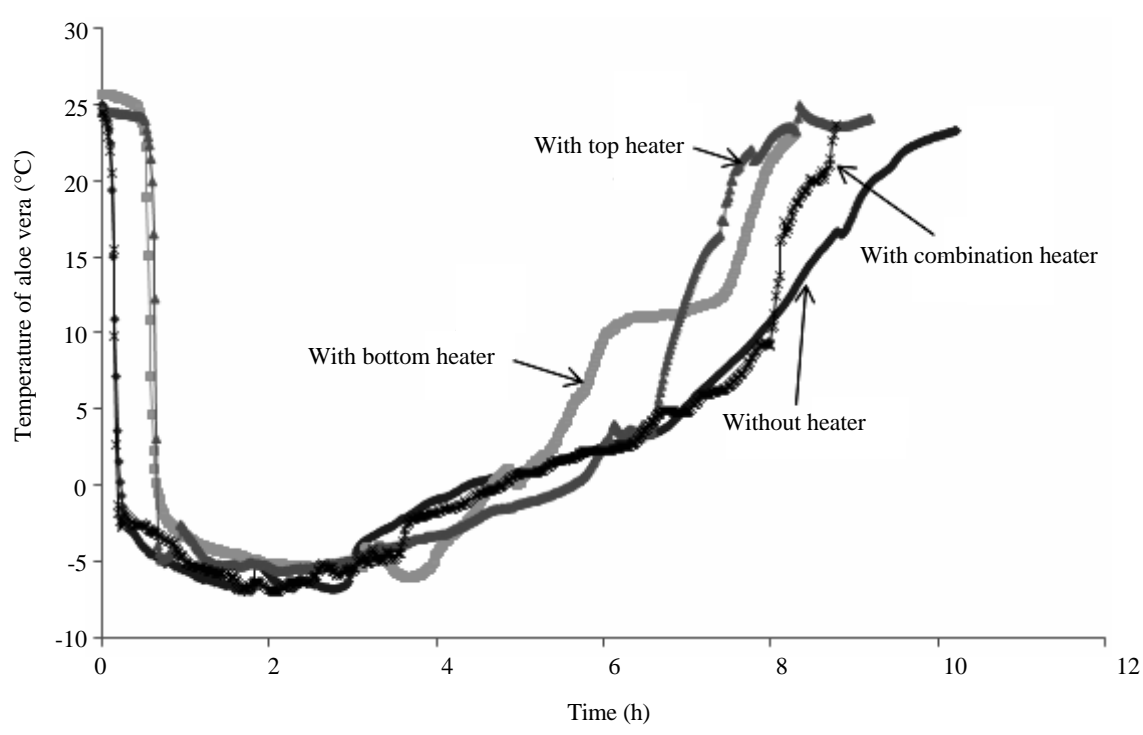

Fig. 6: Profile of aloe vera temperatur during drying process

Table 1: Initial and final moisture content from Eq. 1

\begin{tabular}{|c|c|c|c|c|c|c|c|c|c|c|}
\hline \multirow[b]{2}{*}{ No. } & \multicolumn{2}{|c|}{ Heating condition } & \multicolumn{2}{|c|}{ Heating temperature $\left({ }^{\circ} \mathrm{C}\right)$} & \multicolumn{2}{|c|}{ Weight (g) } & \multirow[b]{2}{*}{$\begin{array}{l}\text { Drying } \\
\text { time (h) }\end{array}$} & \multirow{2}{*}{$\begin{array}{c}\text { Energy } \\
\text { consumption (MJ) }\end{array}$} & \multicolumn{2}{|c|}{ Moisture content $\mathrm{db}(\%)$} \\
\hline & Top & Bottom & Top & Bottom & Initial & Final & & & Initial & Final \\
\hline 1 & Off & Off & 22 & 22 & 45 & 0.60 & 10.2 & 2.41 & 98.7 & 2.5 \\
\hline 2 & On & Off & 30 & 22 & 45 & 0.67 & 9.2 & 2.17 & 98.7 & 12.6 \\
\hline 3 & On & On & 26 & 24 & 45 & 0.65 & 8.8 & 2.08 & 98.7 & 10.0 \\
\hline 4 & Off & On & 22 & 30 & 45 & 0.60 & 8.3 & 1.96 & 98.7 & 2.5 \\
\hline
\end{tabular}

positions (Table 1). Figure 6 shows that the drying time is reduced based on an increase in heating temperature. The reduced drying time means a reduction in energy use (Alibas, 2007). From Eq. 8, we observed that energy consumption could be reduced by as much as $19 \%$ when using the bottom heater at $30^{\circ} \mathrm{C}, 10 \%$ when using the top heater at $30^{\circ} \mathrm{C}$ and $14 \%$ when using the combination heater (top $26^{\circ} \mathrm{C}$ and bottom $24^{\circ} \mathrm{C}$ ). The important objective in this research was reducing energy consumption without adding energy to operate FVD using the condenser's heat loss for heating.

Drying rate: The value of the drying rate of aloe vera was calculated from Eq. 7 (Fig. 7). All variants of the experiment showed that the drying rate reached maximum value at the beginning of the drying process due to a high moisture content in the substance during the first sublimation (Duan et al., 2008). After reaching EMC, its moisture content remained in bound water condition therefore, the drying rate decreased. In other words, the drying rate decreased with drying time in all drying processes. We observed that the processes which affect the drying rate internally are porosity and bulk density (Chakraborty et al., 2006). Results of all experiments indicated that the physical mechanism governing the drying rate was diffusion therefore, heat transfer was not the limiting phenomenon (Arevalo-Pinedo and Murr, 2006). For top and bottom heaters, the top heater in this experiment supplied energy through the dry layer and bottom heating supplied energy through the frozen layer. The maximum drying rate was achieved by the drying process using a frozen layer; this phenomenon is due to the fact that thermal conductivity of a frozen layer is 45 times greater than for a dry layer (Mellor, 1978). In this process, the drying rate also decreased simultaneously with the decrease in drying time. Drying rate was faster when a combination heater was used than when no heater was used but optimal drying occurred when top and bottom heaters were used.

The resulting microstructure and shape of aloe vera: Figure 8 shows the microstructure of aloe vera after heating from the condenser's heat loss in the top and bottom position. Figure 8a shows the result of the drying process without a heater; the structure of the aloe vera appears smooth (not fibrous) and amorphous with interstices. Consequently, there was no change in the structure of the aloe vera as there were some solid granules that did not sublime during the drying process. Figure $8 b$ and $c$ show the same result of the drying process with the bottom and upper heaters but the results differed when no heater was used in that solid granular 


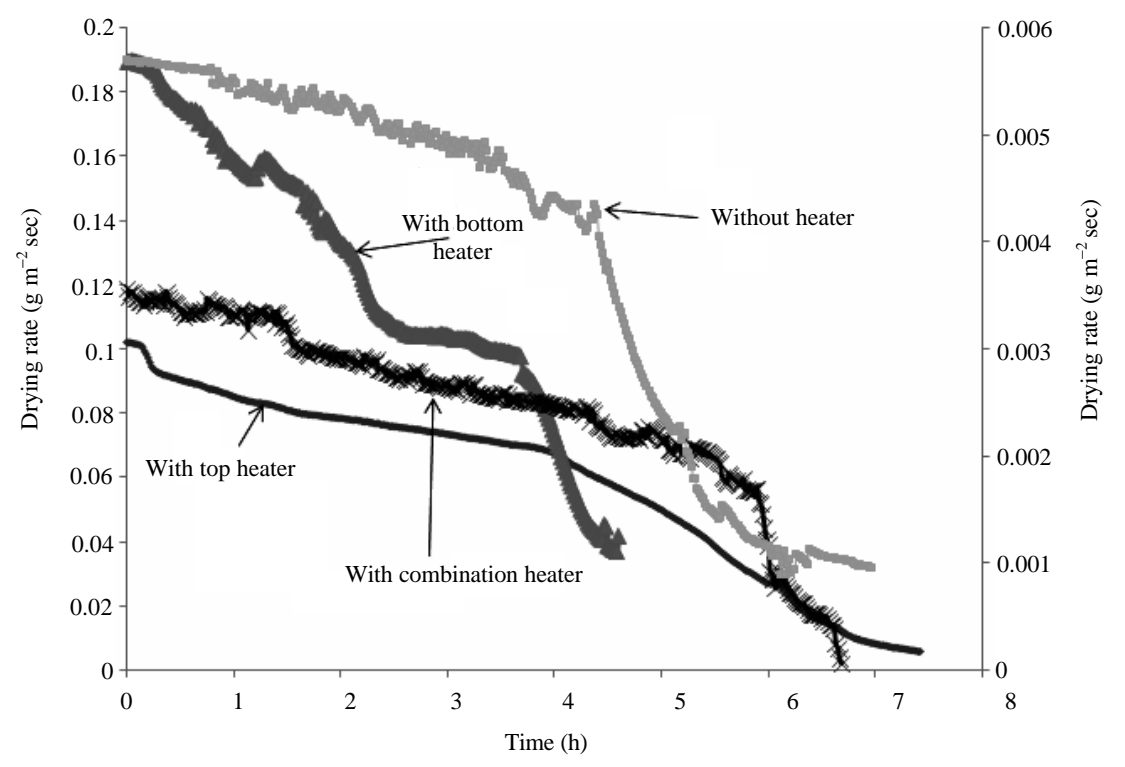

Fig. 7: Drying rate of aloe vera with no heater and with top heater, bottom heater and combination heater
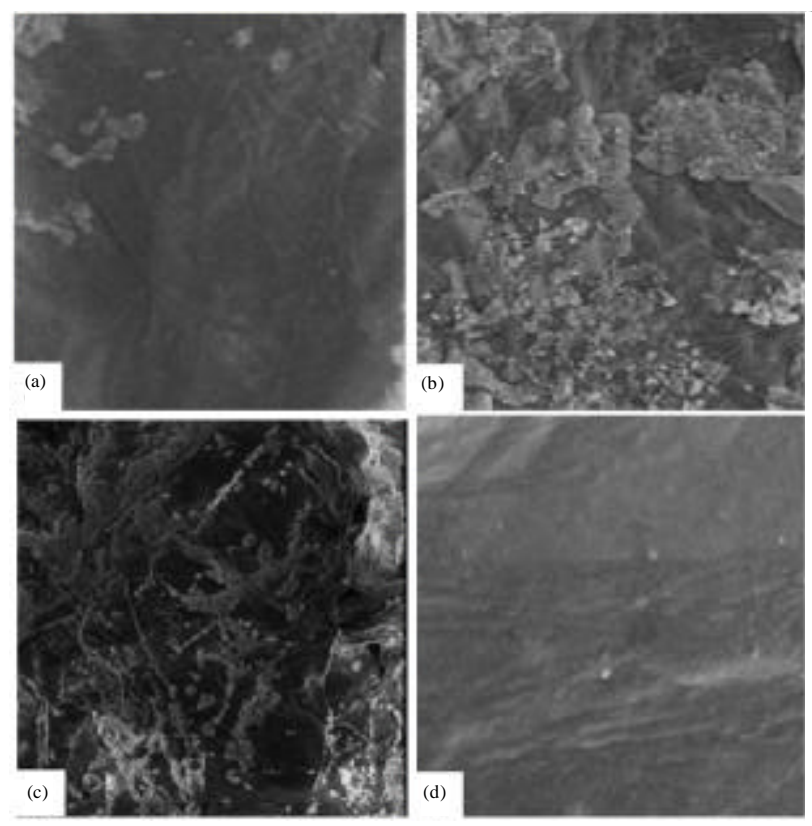

Fig. 8: Microstructure of aloe vera (a): without heater; (b) with bottom heater; (c) with top heater, (d) with combination heater

particles congregated in the microstructure indicating the beginning of the structure's breakdown. The structure had higher collapse and tissue disruption rates caused not only by heating but also by the freezing rate. A high freezing rate retains structural quality of aloe vera better than a slow freezing rate (Acevedo et al., 2007). While using heaters in this research, we observed the formation of a coarse honeycomb structure, similar to the structure observed with the freeze drying of rice at $110^{\circ} \mathrm{C}$ (Lee and Rhee, 2007). In Fig. 8d, the structure of aloe vera is very smooth (not fibrous) with no interstices; it appears as a semisolid congregated granule with no folded layers, meaning there was no change in the structure of the aloe vera. The best microstructure was obtained from FVD without either a heater or a combination heater (top heater $26^{\circ} \mathrm{C}$ and bottom heater $24^{\circ} \mathrm{C}$ ). 

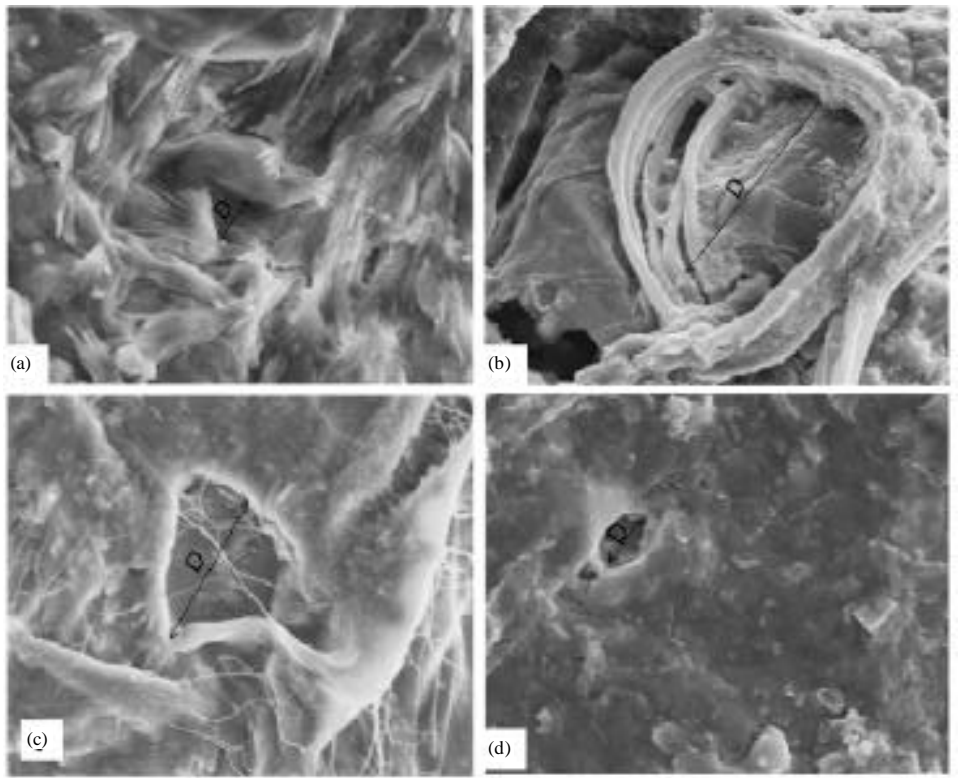

Fig. 9: The pore diameter of aloe vera resulting from increased heater temperature: (a) Without heater, (b) With bottom heater, (c) With upper heater, (d) With combination heater
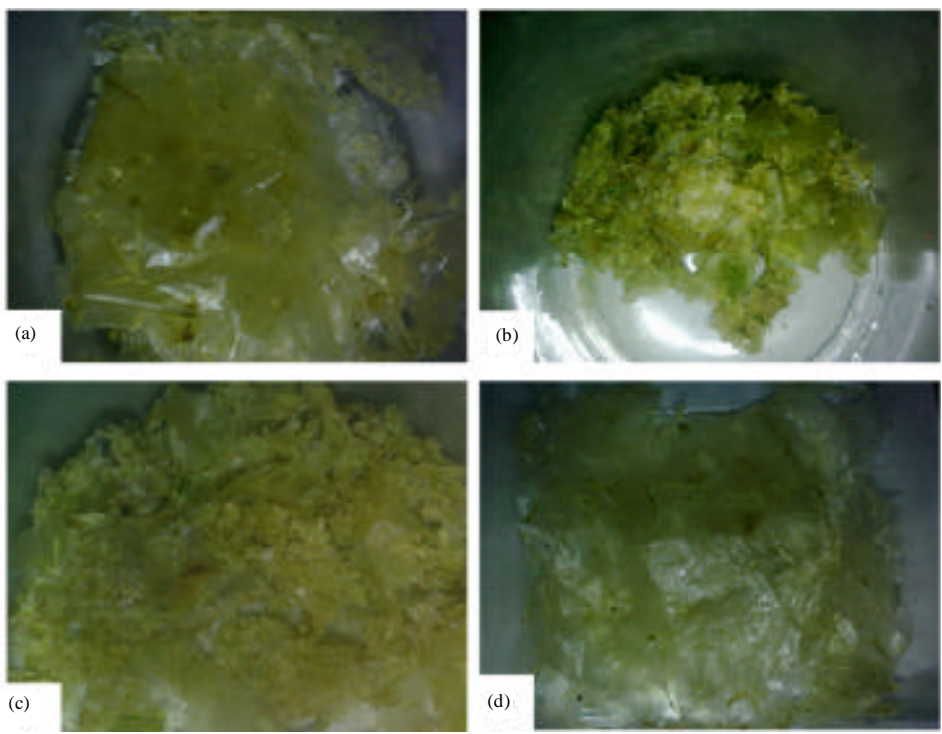

Fig. 10: Shape and color of aloe vera after freeze drying (a) Without heater, (b) With upper heater at $30^{\circ} \mathrm{C}$, (c) With bottom heater at $30^{\circ} \mathrm{C}$, (d) Process with combination heater

Figure 9 shows the effect of heating temperature on pore diameter of aloe vera. From experiments using microwave freeze drying, microwave applications provided dried products with an expanded porous structure (Wang et al., 2010; Huang et al., 2011). A similar observation was made regarding an increase in the pore diameter of rice as an effect of heating temperature (Lee and Rhee, 2007). We also noted that ice sublimation increased the formation of pores and cavities while cells still retained their original shapes, resulting in high porosity and loss of elasticity of the cellular structure (Deng and Zhao, 2008). We demonstrated that increasing heater temperature increases pore diameter of aloe vera's microstructure. Increasing pore diameter subsequently increases drying rate and reduces the drying time.

Figure 10 shows the shape and colour of the final product from FVD. Figure 10 (a) represents the shape and color of aloe vera after freeze drying without a heater; it 


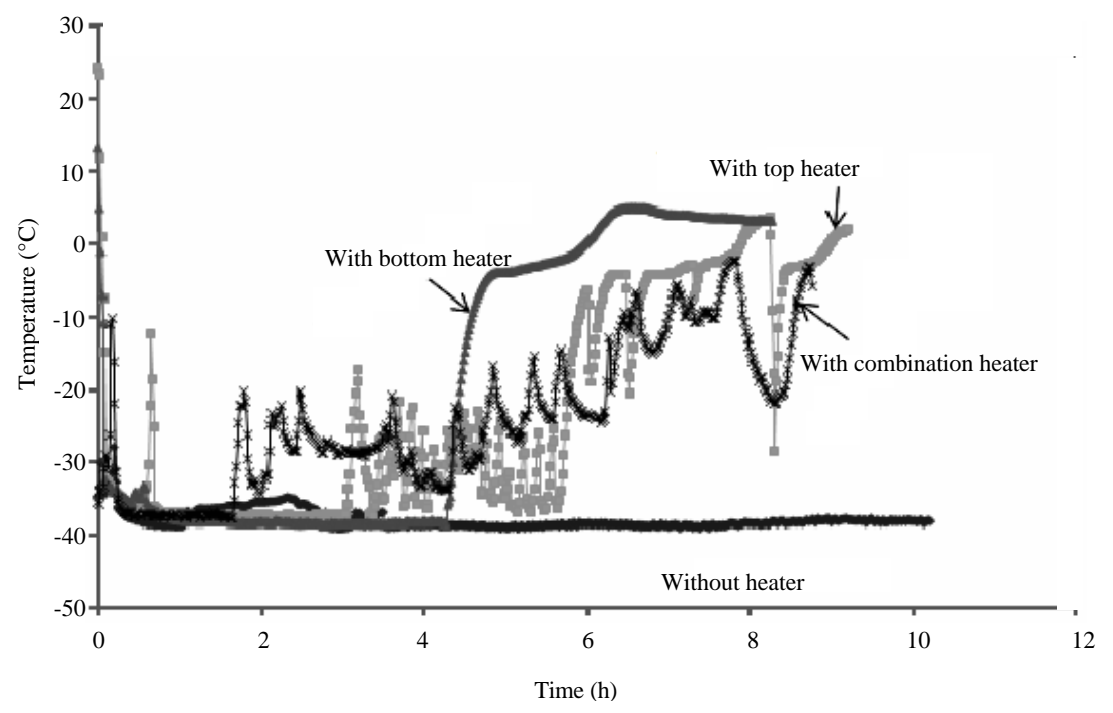

Fig. 11: Profile temperature of cold trap/evaporator during drying process

resembles cotton, appears very smooth and is fading in color. Figure $10 \mathrm{~b}$ use of an upper heater resulted in a granular-shaped product that is not smooth; no changes in the green color of aloe vera appear because the moisture content of material is still high. Figure 10c, use of a bottom heater resulted in a product similar to (b) in its granular shape but a burning of its color resulted from a drying time that was too long. Figure 10d, the shape and colour are the same as Fig. 10a, resembling cotton and very smooth. Figure 10a and d products from freeze drying aloe vera are desirable for their shape. The best condition is shown in Fig. 10d because it retained a good shape and microstructure after freeze drying with a technique that requires less consumption of energy.

Profile of cold trap: Figure 11 shows the profile of a cold trap at various temperatures. Without a heater, the temperature of a cold trap increases and fluctuates at the beginning of the freezing process because of an increasing cooling load from latent heat material taken by the evaporator. The temperature of the cold trap increases during sublimation because of cooling load from drying rate of material which moisture from material can be frozen by evaporator and then the temperature will be stable. By using a heater, the temperature of the evaporator (cold trap) increases and remains unstable until the end of the process because the sources of the cooling load not only comes from the material but also from heaters (top, bottom and combination).

\section{CONCLUSION}

An increase in the drying rate for FVD can be achieved by adding top, bottom and combination heaters. Optimal reduction in the amount of energy used (19\%) is obtained from use of the bottom heater. FVD is effective in removing $96.2 \%$ of moisture content but results depend on drying time.

Investigation of the microstructure showed that most microstructure changes were indicated by congregated granular solidification and folded layers and also by changes in pore diameter in response to heating temperatures and long drying times. Using the condenser's heat loss for heating affected the temperature of the cold trap due to the increasing cooling load of the evaporator.

\section{ACKNOWLEDGEMENT}

The researchers acknowledge the financial support from DRPM UI (Research Centre of UI) Contract: DRPM/ RSN-UI/2011/1/10721.

\section{Notation:}

\section{NOMENCLATURE}

$\mathrm{q}=$ Heat flux, $\mathrm{J}\left(\mathrm{m}^{-2} \mathrm{~s}\right)$

$\mathrm{L}=$ Thickness of sample $(\mathrm{m})$

$\mathrm{T}=$ Temperature $\left({ }^{\circ} \mathrm{C}\right)$

$\mathrm{x}=$ Thickness of dried aloe vera $(\mathrm{m})$

$\mathrm{N}=$ Mass flux $\left(\mathrm{g} \mathrm{m}^{-2} \mathrm{sec}\right)$

$\mathrm{t}=$ Time, $\mathrm{h}(\mathrm{h})$

$\mathrm{h}_{1}=$ Energy required for vacuum pump $\left(\mathrm{kJ} \mathrm{sec}^{-1}\right)$

$\mathrm{h}_{2}=$ Energy required for refrigeration system $\left(\mathrm{kJ} \mathrm{sec}^{-1}\right)$

$\mathrm{h}_{3}=$ Energy required for ice sublimation $\left(\mathrm{kJ} \mathrm{sec}^{-1}\right)$

$\mathrm{H}_{\mathrm{c}}=$ Energy required for total time process (MJ)

$\mathrm{W}_{\mathrm{e}}=$ Amount of moisture removed during the drying process $(\mathrm{kg})$

\section{Greek letters:}

$\Delta \mathrm{L}=$ Distance of frozen surface from the top (m) 
$\lambda=$ Thermal conductivity, $\mathrm{J} /$ (m.s.K)

$\Delta \mathrm{h}=$ Latent heat of sublimation of ice $\left(\mathrm{J} \mathrm{g}^{-1}\right)$

\section{Subscripts:}

$\mathrm{wv}=$ water vapor

$\mathrm{h}=$ Heating

$\mathrm{f}=$ Frozen

\section{REFERENCES}

Acevedo, N.C., V. Briones, P. Buera and J.M. Aguilera, 2007. Microstructure affects the rate of chemical, physical and color changes during storage of dried apple discs. J. Food Eng., 85: 222-231.

Alibas, I., 2007. Energy consumption and colour characteristics of nettle leaves during microwave, vacuum and convective drying. Biosyst. Eng., 96: 495-502.

Arevalo-Pinedo, A. and F.E.X. Murr, 2006. Kinetics of vacuum drying of pumpkin (Cucurbita maxima): Modeling with shrinkage. J. Food Eng., 76: 562-567.

Artnaseaw, A., S. Theerakulpisut and C. Benjapiyaporn, 2010. Drying characteristics of Shiitake mushroom and Jinda chili during vacuum heat pump drying. Food Bioprod. Process., 88: 105-114.

Belyamin, T., A.H. Hadi, K. Purwadaria and M.I. Alhamid, 2007. The application of freeze vacuum and heating from top and bottom on freeze vacuum drying. J. Agric. Eng., 21: 235-248.

Carapelle, A., M. Henrist and F. Rabecki, 2001. A study of vacuum freeze-drying of frozen wet papers. Dry. Technol., 19: 1113-1124.

Chakraborty, R., A.K. Saha and P. Bhattacharya, 2006. Modeling and simulation of parametric sensitivity in primary freeze-drying of foodstuffs. Separat. Purif. Technol., 49: 258-263.

Deng, Y. and Y. Zhao, 2008. Effect of pulsed vacuum and ultrasound osmopretreatments on glass transition temperature, texture, microstructure and calcium penetration of dried apples (Fuji). LWT - Food Sci. Technol., 41: 1575-1585.

Dincer, I., 2003. Refrigeration Systems and Applications. 1st Edn., John Wiley and Sons, Ltd., New York.

Duan, X., M. Zhang, X. Li and A.S. Mujumdar, 2008. Ultrasonically enhanced osmotic pretreatment of sea cucumber prior to microwave freeze drying. Dry. Technol., 26: 420-426.

George, J.P. and A.K. Datta, 2002. Development and validation of heat and mass transfer models for freeze-drying of vegetable slices. J. Food Eng., 52: 89-93.

Ghio, S., A.A. Barresi and G. Rovero, 2000. A comparison of evaporative and conventional freezing prior to freeze-drying of fruits and vegetables. Food Bioprod. Process., 78: 187-192.
Holkeboer, D.H., D.W. Jones and F. Pagano, 1993. Vacuum Technology and Space Simulation. American Institute of Physics, New York, ISBN: 9781563961236, Pages: 339.

Huang, L., M. Zhang, A.S. Mujumdar and R. Lim, 2011. Comparison of four drying methods for restructured mixed potato with apple chips. J. Food Eng., 103: 279-284.

Idrus, A., M. Nasruddin and M. Yulianto, 2010. Characteristic of frezze vacuum drying aloe vera with utilization of heat loss condenser and cold trap from R404. National Seminar SNTI'10 Trisakti University.

Lee, S.W. and C. Rhee, 2007. Effect of heating condition and starch concentration on the structure and properties of freeze-dried rice starch paste. J. Food Res. Int., 40: 215-223.

Mellor, J.D., 1978. Fundamentals of freeze-drying. Academic Press, Bristol, UK., ISBN: 9780124900509 , Pages: 386.

Menlik, T., M.B. Ozdemir and V. Kirmaci, 2010. Determination of freeze-drying behaviors of apples by artificial neural network. Expert Syst. Appl., 37: 7669-7677.

Mujumdar, A.S. and C.L. Law, 2010. Drying technology: Trends and applications in postharvest processing. Food Bioprocess Technol., 3: 843-852.

Mujumdar, A.S., 2008. Guide to Industrial Drying: Principles, Equipment and New Developments. Three S Colors Publications, Mumbai, ISBN: 9788190737135, Pages: 371.

Njintang, N.Y., M.L. Parker, G.K. Moates, C.B. Faulds and A.C. Smith, 2008. Microstructure and creep-recovery characteristics of achu (a taro based paste) made from freeze dried taro chips as affected by moisture content and variety. J. Food Eng., 87: 172-180.

Oetjen, G.W. and P. Haseley, 2004. Freeze-Drying. 2nd Edn., Wiley-VCH., Weinheim, ISBN: 9783527306206 , Pages: 395.

Sharma, G.P. and S. Prasad, 2006. Specific energy consumption in microwave drying of garlic cloves. Energy, 31: 1921-1926.

Shishehgarha, F., J. Makhlouf and C. Ratti, 2002. Freeze-drying characteristics of strawberries. Dry. Technol., 20: 131-145.

Wang, J. and K. Sheng, 2006. Far-infrared and microwave drying of peach. LWT Food Sci. Technol., 39: 247-255.

Wang, R., M. Zhang and A.S. Mujumdar, 2010. Effects of vacuum and microwave freeze drying on microstructure and quality of potato slices. J. Food Eng., 101: 131-139. 